\section{$\underset{\substack{\text { hommes } \\ \text { \& migrations }}}{ }$}

\section{Hommes \& migrations}

Revue française de référence sur les dynamiques

migratoires

$1295 \mid 2012$

Algérie - France : une communauté de destin

\title{
Yahia Belaskri et Elisabeth Lesne, Algéries 50
}

Magellan \& Cie/CNHI, 2012, 287 pages, 19,50 euros

\section{Mustapha Harzoune}

\section{(2) OpenEdition}

\section{Journals}

\section{Édition électronique}

URL : http://journals.openedition.org/hommesmigrations/1100

DOI : 10.4000/hommesmigrations. 1100

ISSN : 2262-3353

\section{Éditeur}

Musée national de l'histoire de l'immigration

\section{Édition imprimée}

Date de publication : 1 janvier 2012

Pagination : 182-183

ISSN : 1142-852X

\section{Référence électronique}

Mustapha Harzoune, «Yahia Belaskri et Elisabeth Lesne, Algéries 50 », Hommes \& migrations [En ligne], 1295 | 2012, mis en ligne le 29 mai 2013, consulté le 22 septembre 2020. URL : http:// journals.openedition.org/hommesmigrations/1100; DOI : https://doi.org/10.4000/ hommesmigrations. 1100

Ce document a été généré automatiquement le 22 septembre 2020.

Tous droits réservés 


\title{
Yahia Belaskri et Elisabeth Lesne,
}

\section{Algéries 50}

Magellan \& Cie/CNHI, 2012, 287 pages, 19,50 euros

\author{
Mustapha Harzoune
}

\section{RÉFÉRENCE}

Yahia Belaskri, Elisabeth Lesne, Algéries 50, Magellan \& Cie/CNHI, 2012, 287 pages, 19,50 euros

1 Algéries 50 est un ouvrage collectif qui rassemble 24 contributions autour du cinquantenaire de l'indépendance algérienne. Des Algériens du cru y croisent d'autres, nés des bifurcations de l'histoire, et des Français mêlés, qu'un fil plus ou moins épais, plus ou moins fragile, relie à cette terre et à ses hommes. Sur la couverture figure, au pluriel, le mot "Algéries". Et ces Algéries scandent, dessinent, pétrissent, aussi, l'histoire de France. Le propre de ce type d'entreprise éditoriale est bien d'offrir une explosion de sensibilités, une tripotée de regards, intimes, rétrospectifs ou prospectifs, de tons et de genres. Ici se côtoient littérature, témoignages, fiction, récits, articles, confessions, souvenirs... Le livre est organisé en cinq entrées, soigneusement nommées : "Tropismes algériens", "Indépendance amère", "Ancrages", "Traversées" et "Butin de guerre".

2 Si tous les chemins ne mènent pas à Alger, ils sont nombreux à converger vers cette terre gorgée de soleil et de générosité. Par une myriade d'insoupçonnables radicelles, l'Algérie et la France ne cessent de croiser, mêler, entremêler, enlacer leur destin, leur histoire, les hommes et les mots : des années d'enseignement à Alger pour l'un, un père pour l'autre, des échanges professionnels, l'éveil à la conscience politique et à la citoyenneté dans et par la guerre d'Algérie pour une génération ou par "la voie de l'amitié et par les sentiers hasardeux du cœur" (Nathalie Philippe).

3 Vues de France, les contributions les plus importantes sont portées par les générations qui ont hérité de ces cinq décennies d'histoire commune. "Un héritage sans testament", 
selon la formule célèbre, pas facile à porter, mais dont les dépositaires, à la croisée de tous les chemins, forment les plus beaux fruits et les plus prometteuses semailles.

Ils sont signés notamment par Elsa Dassi, Rémi Yacine et Mabrouck Rachedi. Dans "Dissimulée", un texte au style pétillant et un brin persiffleur, Elsa Dassi montre comment la rencontre avec une vieille Algérienne va lézarder les constructions et les certitudes de la narratrice : elle ne peut plus dissimuler son métissage, fuir une partie d'elle-même, fille d'un Algérien et d'une Française : “Tout se métisse. Rien n'est lisse."

Chez Rémi Yacine, plus batailleur, une gamine demande à son père si la photo trouvée sur Internet n'est pas celle de son grand-père. Suit la triste histoire d'une famille algérienne et de l'exil en France du narrateur en pleine décennie noire. Il y rencontre Gaëlle. Ensemble ils ont une fille, Sarah - ses "racines". Elle interroge son papa qui, iconoclaste en ces temps de gnangnan mémoriel, énonce, in petto: "Oublie donc l'arbre généalogique, joue donc à la poupée ou à la PlayStation. Dégotte un amoureux pour refaire le monde, et laisse le mien mourir en silence. (...) Notre présent est plus beau que le passé." Si d'autres matins se lèvent, d'autres combats s'annoncent aussi : "Mais toi, Sarah, elle est où ta place? Que deviendras-tu? Quand un ministre dit qu'il y a trop d'Arabes en France, ça va; quand c'est la moitié du gouvernement qui le dit... Sarah, il y a plusieurs moitiés, la logique est restrictive : tu es moitié bretonne, moitié kabyle, moitié arabe, moitié africaine, moitié française. $T u$ es plusieurs moitiés, tu es nombreuse, multiple."Mabrouck Rachedi remonte cet arbre généalogique, jusqu'à la guerre et l'exil paternel. Mais, "en métropole, la valeur d'un immigré est proportionnelle à ses capacités à raser les murs et à les construire". Et pourtant, c'est cette génération des pères qui, par une sorte de pirouette taoïste, sans volition, si ce n'est de travailler pour améliorer le sort des siens, sans bruit et sans fureur, a accouché d'une nouvelle société, bouleversé les frontières, pulvérisé les identités et décloisonné les fermetures. C'est cela aussi le cinquantième anniversaire de l'indépendance algérienne : le clin d'œil d'un vieil immigré algérien adressé à ses douze enfants, au soir d'une vie passée en France.

Chacun célèbre cet anniversaire à partir de son expérience. Nathalie Philippe et Christiane Chaulet-Achour avec les romanciers algériens - et français d'origine algérienne - par trop "délaissés", ignorés en France. Alice Cherki, José Lenzini, Abdelkader Djemaï ou Yves Ouahnon qui rêve d'un Oran fraternel aux cultures arabe, française espagnole et juive mêlées le font en évoquant le passé, l'enfance. Yahia Belaskri raconte l'amitié, la fraternité même, de Jeff le pied-noir et de Fatah l'Algérien. Fatima Besnaci-Lancou revient sur une honte française : le sort des harkis revisité par les yeux d'un enfant qui attend sa mère dans le camp de Rivesaltes.

7 In situ, des Algériens ne soufflent pas des bougies. Ils lancent des flammes : "Pourquoi tu vantes l'indépendance en sachant que ceux qui ont remplacé les colons sont pires qu'eux?" demande Arezki Métref dans un texte percutant où le présent et le passé se télescopent à travers deux murs et deux graffitis. Rachid Mokhtari trace un fil rouge sang qui part de Bugeaud et court jusqu'à Antar Zouabri (chef du GIA). Et pourtant, "De funérailles, il n'y en eut point dans l'histoire des blessures du pays. Des enfouissements, des charniers..." À Laghouat, le 4 décembre 1852, la France extermina 2500 habitants sur les 3000 que comptait la ville. Seuls 500 réussirent à s'échapper. Leurs descendants sont des “ miraculés" et Lazhari Labter, l'un d'entre eux, attend que son pays, cinquante ans après l'indépendance, "accède à la liberté".

8 Brahim Hadj-Slimane dénonce la violence et le sort des "perdants". Leïla Marouane évoque les femmes lumineuses de son enfance, l'islamisme noir, les menaces et 
l'agression subies, l'indépendance devenue "amère" : "Parce que les révolutions ne profitent qu'aux lâches." Comment être "arabe" et y "échapper" ? demande Anouar Benmaleck. Pour "trouver sa place" entre les enfermements nationalistes, essentialistes ou religieux, il termine son texte par un mot : "Résistez." 